\title{
Modelling, simulation and optimization of Bai-Hasan wide distillate hydrodesulfurization
}

\author{
Shymaa Ali Hameed \\ Chemical Engineering Department, College of Engineering, Tikrit University, Iraq
}

Rec. 30 Dec, 2012 Accept. 21 Feb, 2013

\begin{abstract}
Bai-Hasan wide distillate derived from Bai-Hasan crude oil (having a boiling range from initial boiling point to $823 \mathrm{~K}$ ), was hydrotreated in a Trickle Bed Reactor using the commercial cobaltmolybdenum on alumina $\left(\mathrm{Co}-\mathrm{Mo} / \gamma-\mathrm{Al}_{2} \mathrm{O}_{3}\right)$ as a catalyst. The reactor temperature was varied from 603 to $673 \mathrm{~K}$ and the liquid hourly space velocity (LHSV) from 0.6 to $1.9 \mathrm{hr}^{-1}$, keeping constant hydrogen to oil ratio $\left(\mathrm{H}_{2} / \mathrm{Oil}\right)$ and hydrogen pressure at $350 \mathrm{~L} / \mathrm{L}$ and $3 \mathrm{MPa}$, respectively. In order to obtain useful models for hydrodesulfurization (HDS) process, the accurate estimation of kinetic model of the relevant reaction scheme were required. Thus, kinetic model of sulfur removal was studied by using an optimization technique based on pilot plant experiment. The minimization of the sum of the squared errors $(S S E)$ between the experimental and estimated concentrations of sulfur compound in the products was used as an objective function to determine the kinetic parameters via non-linear regressions. The predicted product concentration showed very well agreement with the experimental data for a wide range of operating conditions with absolute average errors less than $5 \%$.
\end{abstract}

Keywords: Hydrotreating, kinetic Model, hydrodesulfurization, Trickle-bed reactor, Optimization.

\section{Introduction}

Petroleum has remained a significant part of our lives and will do so for the next decades. The fuels that are produced from petroleum supply more than half of the world's total supply of energy. Gasoline, kerosene, and diesel oil provide fuel for automobiles, tractors, trucks, aircraft, and ships (Hsu and Robinson, 2006).

Petroleum is by far the most commonly used source of energy, especially as a source of liquid fuels. World energy usage has increased by an average of $1.7 \%$ annually from 19972007 (Stacy et al., 2008). In fact, according to the vast use of petroleum, the last 100 years could very easily be dubbed as the oil century (Ryan, 1998). As a result, petroleum is projected to be the major source of energy over the coming decades. In this respect, fossil fuels and their associates (heavy oils and residua) are extremely significant in any energy scenario, particularly those scenarios that relate to the production of liquid fuels
(Ancheyta and Speight, 2007; Khalfallah, 2009).

It is a fact that in recent years, the average quality of petroleum has declined, which has caused the nature of crude oil refining to change considerably (Swain, 1998). This, of course, has led to the need for managing crude quality more effectively through evaluation and product specifications (Waguespack and Healey, 1998; Speight, 2006). The declining reserves of light oils in the world have resulted in an increasing need for developing choices to remove the impurities (mainly sulfur compounds) and upgrade the heavy feedstocks, specifically heavy oil and bitumen. This has resulted in a diversity of operation choices that specialize in contaminants removal during refining, particularly sulfur compounds (Armstrong et al., 1997).

The presence of sulfur compounds in crude oil or oil derivatives have a big impact upon the quantity of oil products in addition to the harm it can cause. Sulfur compounds lead to

\begin{tabular}{ll}
\hline * Corresponding author: & 49 \\
Dr. Shymaa Ali Hameed &
\end{tabular}


environmental pollution through atmospheric contamination by oxidization resulting from combustion forming sulfur dioxides that will be oxidized later with ultraviolet rays to $\mathrm{SO}_{3}$. Then it reacts with atmospheric water to form sulfuric acid, which causes many diseases after inhaling air like asthma and shortness of breath. It also leads to soil pollution with acid materials, decreases the life of machinery, corrodes of pipes, machines and equipment, affecting the additives used for the purpose of increasing the octane number, reduce the activity of Tetra Ethyl Lead (TEL) added to gasoline in addition to stinking odour and reducing the catalyst activity (Andari et al., 1996; Jarullah et al., 2011a). As a result, the engine metal will erode, leading to the destruction of metallic parts. The same is true with gas oil and diesel fuel as well as lubricating oils. Also, their emissions are very dangerous to human safety and environment. Hence, the environmental legislations have enforced substantial decrease of sulfur compounds in fuels for getting high quality products (Ali et al., 1986; Jary, 1994).

Many scientists have studied the probability of getting rid of such compounds in order to meet the challenges associated with petroleum refining operations. Thus, a number of technologies have been developed to improve fuel quality into more valuable transportation fuels. Amongst these technologies, the catalytic hydrodesulfurization process (HDS), which is regarded one of the most important processes in petroleum refining industries that has the capacity for increasing the distillates production and to removing the impurities such as sulfur, nitrogen, metals and asphaltenes (Jarullah et al., 2011b,c).

Hydrodesulfurization is the most common process units in the modern petroleum refining industry. There are more than 1300 units and the world's hydrodesulfurization capacity is nearly half as large as the world's crude distillation capacity (Stell, 2003). In the petroleum refining industry, HDS reactions are carried out in Trickle Bed Reactors (TBRs). These reactors in which three phases, liquid (oil), gas (mostly hydrogen) and solid catalyst particle are frequently preferred due to ease of control and used for different feedstocks (Macı'as and Ancheyta, 2004).

TBR reactors have been the topic of various authors, and many investigators have discussed them in reviews (Rodriguez and Ancheyta, 2004; Jarullah et al., 2012). In this study, the main focus is to remove the sulfur compounds by hydrogen (which is the hydrodesulfurization process (HDS) and finding the best kinetic model for Bai-Hasan wide distillate hydrodesulfurization based on experiments using the optimization technique. Here, the modelling, simulation and optimization are carried out by using general process modelling system software and the optimization problem is posed as a NonLinear Programming (NLP) problem and is solved using a Successive Quadratic Programming (SQP) method.

\section{Mathematical Kinetic Model:}

A mathematical model is a set of variables and a set of equations that build relationships among the variables for describing some aspects of the behaviour of the system under investigation. Process models are very profitable and have been employed for operator training, safety systems design, design of operation, as well as operational control systems designs. The improvement of faster computers and advanced numerical methods has enabled modelling and solution of the whole process (Jarullah et al., 2011b).

Building models is one of the major occupations of engineering and science. Models are used because it is too expensive or time consuming or risky to use real system to evaluate plant performance. Models are typically employed in engineering design and optimization because they offer the cheapest and faster way of studying the impacts of changes in design variables on system performance (Jarullah et al., 2011a).

Developing kinetic models for Bai-Hasan wide distillate hydrodesulfurization is not a simple task due to the complexities composition of such reaction and its analysis. Where, sulfur compounds can be found in 
more than one form, such as mercaptane, sulfide, thiophene, benzothiophene, dibenzothiophene besides their alkyl derivatives shapes, and each form is described by its own reactivity and complex reaction ways, which are specific to each feed (Wauquier, 1995). Therefore, the rate of chemical reaction is usually lumped into a single power law reaction (Lababidi et al., 1998).

The kinetic model here is incorporated into an isothermal reactor model and the experimental data for HDS of Bai-Hasan wide distillate cut will be adjusted with a power law kinetic model, where plug flow reactor behaviour is considered. The following mass balance is used to evaluate the sulfur content in reaction products from a set of kinetic parameters:

$\frac{d C_{s u l}}{d \tau}=r_{s u l}=-K_{s u l} C_{s u l}^{n}$

Where, $C_{\text {sul }}$ is the sulfur content in reaction products, $\tau$ is the residence time (1/LHSV), $n$ is the reaction order of HDS process and $K_{\text {sul }}$ is the reaction rate constant for HDS reaction, which can be calculated utilizing the Arrhenius equation as follows:

$K_{\text {sul }}=A_{\text {sul }}^{0} \exp \left(-\frac{E A_{s u l}}{R T}\right)$

$E A_{\text {sul }}$ is the activation energy, $A_{\text {sul }}^{0}$ is the preexponential

factor, $T$ is the reaction temperature and $R$ is the global constant.

\section{Parameters of the Kinetic Model:}

In order to estimate the best values of kinetic parameters for all experiments, a non-linear regression is used to simultaneously obtain the reaction orders of sulfur $(n)$, the activation energy $\left(E A_{\text {sul }}\right)$ and pre-exponential factor $\left(A_{\text {sul }}^{0}\right)$. The major focus is to accurately calculate these parameters. This approach is applied using the sum of the squared errors (SSE) between the experimental sulfur contents in each product at different operating conditions $\left(C_{\text {sul }_{i}}^{\exp }\right)$ and predicted values of sulfur contents in products $\left(C_{s u l_{i}}^{c a l}\right)$, where the objective function is minimized via optimization technique, as:

$$
\text { SSE }=\sum_{i=1}^{N \text { Dusa }}\left[C_{\text {sul }}^{\exp _{i}}-C_{\text {sul }}^{\text {cal }}\right]^{2}
$$

\section{Optimization Problem Formulation for Parameter Estimation:}

The optimization problem can be presented as follows:

Given Feedstock composition, reaction temperature, LHSV.

Optimize Reaction orders $(n)$, activation energy $\left(E A_{\text {sul }}\right)$ and pre-exponential factor $\left(A_{\text {sul }}^{0}\right)$ under different operating conditions.

Minimize The sum of squared errors (SSE).

Subject to Process constraints and linear bounds on all optimization variables.

Mathematically, the optimization problem can be stated as:

Min SSE

n, $E A_{\text {sul, }} A_{\text {sul }}^{0}$

s.t $f(z, x(z), \quad \bar{x}(z), u(z), \underline{v})=0$ (model, equality constraints)

$n^{L} \leq n \leq n^{U}$

(inequality constraints)

$E A_{\text {sul }}{ }^{L} \leq E A_{\text {sul }} \leq E A_{\text {sul }}{ }^{U} \quad$ (inequality constraints)

$A^{0}{ }_{\text {sul }}{ }^{L} \leq{A^{0}}^{0}{ }_{\text {sul }} \leq A^{0}{ }_{\text {sul }} U \quad$ (inequality constraints)

$f(z, x(z), \bar{x}(z), u(z), \underline{v})=0$, represents the process model presented above, where $z$ is the independent variable, $x(z)$ gives the set of all differential and algebraic variables, $\bar{x}(z)$ denotes the derivative of differential variables, $u(z)$ is the control variables, $\underline{v}$ represents the design variables (independent constant parameters), $U$ and $L$ are the upper and lower pounds.

\section{Experimental Work: \\ Feed Oil:}

The liquid feed stock is Bai-Hasan wide distillate derived from Bai-Hasan crude oil (its boiling range from initial boiling point to 823 $\mathrm{K})$. This fraction has been obtained under atmosphere and vacuum distillation process of Bai-Hasan crude oil. Table (1) shows the properties of the liquid feed stock used in this work. 


\begin{tabular}{|c|c|}
\hline Properties & Value \\
\hline Sulfur content $(\mathrm{wt} \%)$ & 1.82 \\
\hline Specific gravity at $15.6^{\circ} \mathrm{C}$ & 0.8646 \\
\hline API & 32.12 \\
\hline Viscosity at $40^{\circ} \mathrm{C}(\mathrm{cSt})$ & 8.326 \\
\hline
\end{tabular}

Table (1): The properties of Bai-Hasan wide distillate.

Catalyst:

The catalyst used for the HDS process in this work was the commercial cobaltmolybdenum on alumina $\left(\mathrm{Co}-\mathrm{Mo} / \gamma-\mathrm{Al}_{2} \mathrm{O}_{3}\right)$ type catalyst. The catalyst used was extrudates with a cylindrical shape and an equivalent diameter of $1.8 \mathrm{~mm}$. A $60 \mathrm{~g}$ of catalyst was discharged to the reactor (Trickle Bed Reactor) and dried at 393K for 2 hour. A ceramic ball was putted in a two layer above and under the catalyst layer.

Catalyst activation was performed prior to feed introduction. This catalyst presulfiding is accomplished by a solution of carbon disulfide in commercial gas oil at $477 \mathrm{~K}, 20 \mathrm{bar}$ hydrogen pressure and $2.6 \mathrm{hr}^{-1}$ LHSV for $4 \mathrm{hr}$, and at $573 \mathrm{~K}, 20 \mathrm{bar}, 1 \mathrm{hr}^{-1}$ and $27 \mathrm{l} / \mathrm{hr}$ hydrogen flow for $16 \mathrm{hr}$.

\section{Distillation Process:}

Bai-Hasan wide distillate was gained at atmosphere and vacuum pressure applied to Bai-Hasan crude oil using distillation unit. The distillation unit was operated at atmospheric pressure with the reflux ratio of $3: 5$ until the distillation temperature reached $474 \mathrm{~K}$, then the distillation unit system was connected to a vacuum system. The vacuum system consisted of a high efficiency vacuum pump with highly tightened tube connections to provide a vacuum pressure as low as possible. The vacuum distillation unit was connected to the vacuum pump through a vapour trap at 5 to 6 $\mathrm{mmHg}$ till reaching $461 \mathrm{~K}$ temperature, where the pressure was reduced to $0.1 \mathrm{mmHg}$. Distillation process continuous till temperature reached $543 \mathrm{~K}$ under vacuum pressure, which is equal to $823 \mathrm{~K}$ under normal atmosphere pressure.

\section{Hydrodesulfurization Process:}

Pilot plants play an important role in petroleum refining industries. They are particularly utilized in the assessment of the performance of the catalytic process, providing valuable information that can be used as a predictive tool for industrial performance. In this study, the hydrotreating runs were conducted in a pilot plant continuous high pressure unit employing an up-flow concurrent trickle bed reactor.

The reactor tube was made of stainless steel with an inside diameter $20 \mathrm{~mm}$ and a length of $650 \mathrm{~mm}$. The reactor was operated in isothermal mode by independent temperature control of five zone electric furnaces, which provided an isothermal temperature along the active reactor section. The reactor outlet feeds the high pressure separator where the liquid and gas are separated. Finally, in the gases section, the exiting gas is passed through a gas flow meter before being released. The unit was supplied with a high-pressure dosing pump to introduce the feed oil into the reactor. A calibrated micrometer was fitted in the pump to monitor the feedstock flow rate.

The feedstock and hydrogen pass through the reactor in an up flow mode by a heated high pressure line. The catalyst bed was located between two beds of inert material. The temperature range from 603 to $673 \mathrm{~K}$, and 0.6 to $1.9 \mathrm{hr}^{-1}$ LHSV, and in all the experiments pressure was maintained at $3 \mathrm{Mpa}$ and $350 \mathrm{~L} / \mathrm{L} \mathrm{H}_{2} / \mathrm{Oil}$ ratio.

\section{Results and Discussion:}

The main hydrotreating reactions in this study are hydrodesulfurization (HDS) reactions. The data generated from these experiments are utilized in calculating the kinetic parameters of the model that can represent the hydrodesulfurization reactions.

\subsection{Experimental Results}

The experiments of sulfur removal by hydrogen applied to Bai-Hasan wide distillate derived from Bai-Hasan crude oil have been carried out at different operating conditions. The major effect of operational variables employed in HDT unit and their influence on the reactor performance can be summarized as follows. To improve the sulfur conversion, three procedures can be chosen: increase of 
temperature, decrease of liquid hourly space velocity and increase of pressure. However, there are many limitations that should be taken into account during the HDT process. An increase in reactor temperature will lead to severe hydrocracking reactions and will give undesirable compounds in addition to reduced catalyst life. A decrease in liquid hourly space velocity will decrease the plant capacity, and hence new hydrotreating reactors will have to be added in order to keep the existing production capacity. Also, an increase in hydrogen pressure with high level is not favourable and the partial pressure does not increase owing to existing physical constraints of maximum pressure (Jimenez et al., 2007a,b).

The effect of operating conditions on sulfur content is illustrated in Figures 1 and 2. It has been observed that the sulfur content in all products decreased with increasing temperature and pressure and decreasing liquid hourly space velocity. Similar behaviour has also been reported by many studies for the hydrodesulfurization process using several oily feedstocks (Areff, 2001; Bhaskar et al., 2002; Alvarez and Ancheyta, 2008).

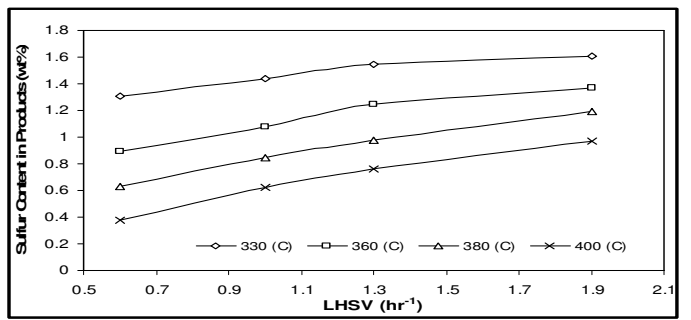

Figure (1): Effect of LHSV on the sulfur content at different temperatures.

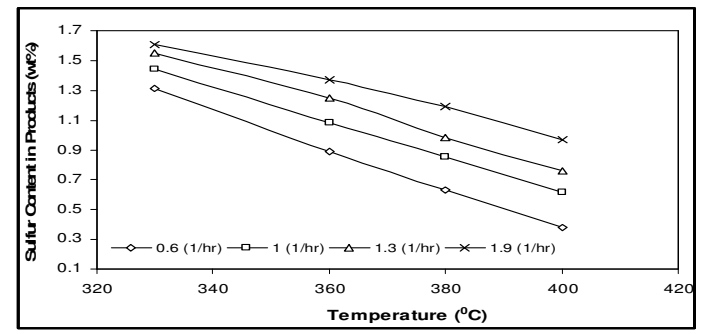

Figure (2): Effect of temperature on the sulfur content at different LHSV.
The high removal of sulfur at high temperatures are due to several reasons, such as the high effectiveness of thiophenic sulfur compounds found in the heavy cuts of this fraction (Ali and Abdul-Karim, 1986). Also, the increase in temperature raises the activation energy, leading to an increase in the number of particles of sulfur compounds interacted. This leads to cleavage of the longsulfur compounds and spread within the catalyst. Furthermore, high temperatures increase the rate of proliferation and osmosis in the pores of the catalyst on the active sites where HDS reactions occur because of the low viscosity (Isoda et al., 1998). Increased sulfur removals by decreasing in LHSV are attributable to increased contact time (residence time) between the molecules of reactants and catalyst, and provide sufficient time for the reaction process (Al-Humaidan, 2004).

\section{Kinetic Parameters Estimation:}

The optimal set of kinetic parameters for HDS reactions have been estimated based upon minimizing the sum of squared error between experimental and calculated results. In this approach, the activation energy $\left(E A_{\text {sul }}\right)$, pre-exponential factor $\left(A^{0}{ }_{s u l}\right)$ and sulfur order $(n)$ were estimated simultaneously. The kinetic parameters obtained were validated against pilot plant experiments and are reported in Table 2.

\begin{tabular}{|l|l|}
\hline Parameters & Value \\
\hline $\mathbf{n}$ & 1.57101 \\
\hline Ea $(\mathbf{J} / \mathbf{m o l e})$ & 88394.6 \\
\hline $\left.\mathbf{A}_{\mathbf{0}}(\mathbf{( w t \% )})^{\mathbf{0 . 5 7 1 0 1}} \mathbf{. h r}^{-1}\right)$ & $1.06328 \times 10^{8}$ \\
\hline SSE & $4.64831 \times 10^{-8}$ \\
\hline
\end{tabular}

Based on the objective function (SSE), the best sulfur order was 1.57101 with activation energy and pre-exponential factor at 88394.6 and $1.06328 \times 10^{8}$, respectively, which means that the parameters calculation by non-linear regression approach is more accurate for this reaction and is typical for lumped kinetics. Several authors have extensively studied the reaction kinetics of hydrodesulfurization 
process of different distillate cuts and reported that HDS reactions follows half to second order kinetics for sulfur (Korsten and Hoffmann, 1996; Kumar et al., 2001; Bhaskar et al., 2002; Rodriguez and Ancheyta, 2004; Mederos and Ancheyta, 2007; Alvarez and Accheyta, 2008).

In order to assessment the kinetic parameters and providing sufficient evidence to make ensure that values of kinetic parameters calculated do correspond to the global minimum of the objective function so that the developed process models is accurate, sensitivity analyses for $n, E A_{\text {sul }}$ and $A_{\text {sul }}^{0}$ values were performed. The information obtained from parametric sensitivity analysis is very useful for optimization and parameter estimation. It gives a clear indication which parameter has the largest influence on the accuracy of the kinetic model. Sensitivity analysis is utilizing for each of the evaluated parameters by means of perturbations of the parameter value and is preferably in the range of $\pm 10 \%$, keeping the other parameters at their nominal values (Resendiz et al., 2007; Alcazar and Ancheyta, 2007; Rao, et al., 2009). For each perturbation in the parameter values, the objective function is re-calculated and then for each parameter the perturbation percentage is plotted against the corresponding value of the objective function as shown in Figure 3 for each parameter. When all the perturbations in all the kinetic parameters give the same minimum of the objective function with their original values ( $0 \%$ perturbation), that means the global minimum has been achieved. On the other hand, if at least one parameter does not give the same minimum than the others at $0 \%$ perturbation, means poor nonlinear parameter evaluation. From Figure 3, it is clearly seen that the evaluated kinetic parameters are the optimum since at $0 \%$ perturbation the perturbations of $n, E A_{\text {sul }}$ and $A^{0}{ }_{\text {sul }}$ give the same minimum of the objective function (SSE) with their original values. Thus, it is demonstrated that the global minimum has been achieved.

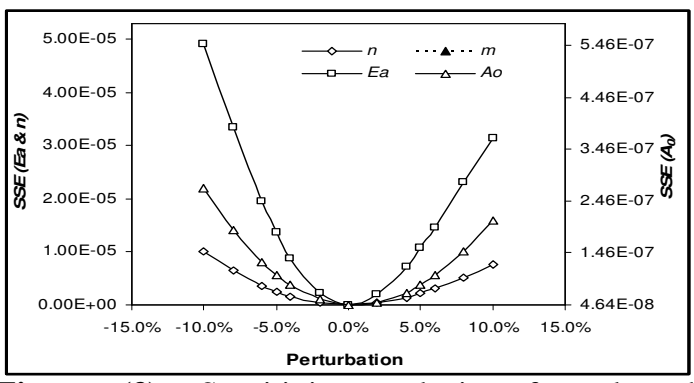

Figure (3): Sensitivity analysis of evaluated parameters for HDS reaction.

It is also observed from this Figure that the reaction order $(n)$ has the biggest impact on HDS kinetic model in comparison to $E A_{\text {sul }}$, and $A^{0}$ sul, respectively. The kinetic model generated by this can be written as:

$-r_{\text {sul }}=1.06328 \times 10^{8} e^{-88394} .6 / R T C_{\text {sul }}^{1.57101}$

A comparison between experimental results and model prediction results for HDS of BaiHasan wide distillate is shown in Tables 4, and plotted in Figure 4 (where the experimental data are represented in the form of points; while the simulation results are represented in the form of curves, each curve representing 4 simulated points). As can be seen from the results, the model was found to simulate the performance of the pilot plant TBR with very well agreement in the range of operating conditions studied here between both concentrations with average absolute error less than $5 \%$ by using non-linear approach.

Figures 5 shows a parity plot of the model for HDS reactions studied in the present work (each point represents simulated (Y-axis) and experimental (X-axis) values at the same time with the same operating conditions for each point). The correlation between the experimental results and simulated sulfur in all products appears to be straight line with a slope close to 1.0 , indicating very good agreement between the measured and predicted results. The model can be used to describe the behaviour of the pilot plant trickle bed reactor at different operating conditions for which experimental data are not available. 


\begin{tabular}{|c|c|c|c|c|c|c|}
\hline \multirow{2}{*}{\multicolumn{2}{|c|}{$\begin{array}{c}\text { Operating Conditions } \\
\mathbf{P}=\mathbf{3 M p a}\end{array}$}} & \multicolumn{2}{|c|}{ Experimental Results } & \multicolumn{3}{|c|}{ Simulated Results } \\
\hline & & \multirow{2}{*}{$\begin{array}{l}\text { Sulfur } \\
(w t \%)\end{array}$} & \multirow{2}{*}{$\begin{array}{c}\text { Conversion } \\
(\%)\end{array}$} & \multirow{2}{*}{$\begin{array}{l}\text { Sulfur } \\
\text { (wt\%) }\end{array}$} & \multirow{2}{*}{$\begin{array}{c}\text { Conversion } \\
(\%)\end{array}$} & \multirow{2}{*}{$\begin{array}{c}\text { Absolute } \\
\text { Error (\%) }\end{array}$} \\
\hline LHSV $\left(\mathbf{h r}^{-1}\right)$ & $\mathbf{T}\left({ }^{\circ} \mathbf{C}\right)$ & & & & & \\
\hline 0.6 & 330 & 1.31 & 28.02 & 1.2737092 & 30.02 & 3.63 \\
\hline 1.0 & 330 & 1.44 & 20.88 & 1.4565894 & 19.98 & 1.14 \\
\hline 1.3 & 330 & 1.55 & 14.84 & 1.5296548 & 15.95 & 1.33 \\
\hline 1.9 & 330 & 1.61 & 11.54 & 1.6129816 & 11.37 & 0.18 \\
\hline 0.6 & 360 & 0.89 & 51.09 & 0.8728671 & 52.04 & 1.96 \\
\hline 1.0 & 360 & 1.08 & 40.66 & 1.1299896 & 37.91 & 4.42 \\
\hline 1.3 & 360 & 1.25 & 31.32 & 1.2476363 & 31.45 & 0.19 \\
\hline 1.9 & 360 & 1.37 & 24.73 & 1.3936630 & 23.42 & 1.69 \\
\hline 0.6 & 380 & 0.63 & 65.38 & 0.6069869 & 66.65 & 3.79 \\
\hline 1.0 & 380 & 0.85 & 53.29 & 0.8709773 & 52.14 & 2.41 \\
\hline 1.3 & 380 & 0.98 & 46.15 & 1.0065124 & 44.69 & 2.63 \\
\hline 1.9 & 380 & 1.19 & 34.61 & 1.1886939 & 34.69 & 0.11 \\
\hline 0.6 & 400 & 0.38 & 79.12 & 0.3886618 & 78.64 & 2.23 \\
\hline 1.0 & 400 & 0.62 & 65.93 & 0.6203904 & 65.91 & 0.06 \\
\hline 1.3 & 400 & 0.76 & 58.24 & 0.7548204 & 58.52 & 0.69 \\
\hline 1.9 & 400 & 0.97 & 46.70 & 0.9531901 & 47.63 & 1.76 \\
\hline
\end{tabular}

Table (4): Simulation data of the pilot plant-TBR versus experimental data for Bai-Hasan wide distillate hydrodesulfurization.

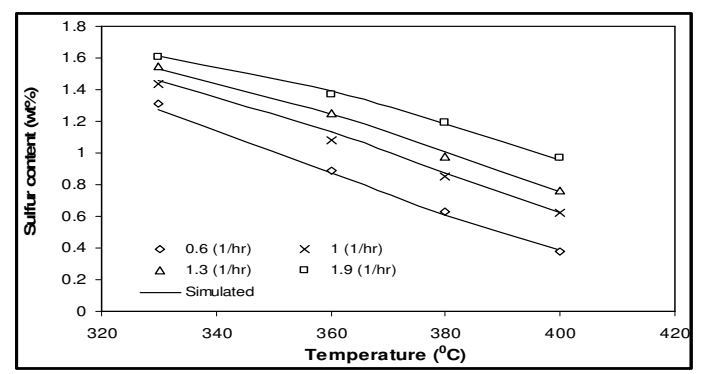

Figure (4): Experimental data (points) and simulated (lines) variation of outlet sulfur content vs. temperature at different LHSV.

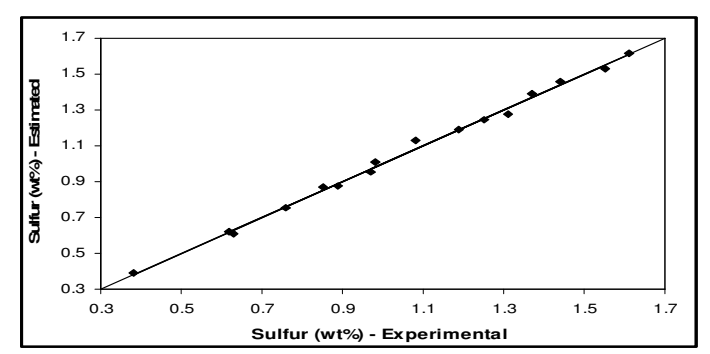

Figure (5): Comparison between experimental and estimated concentrations of sulfur

\section{Conclusions:}

Impurities-free high-quality energy sources are more in demand than ever owing to regulations on environmental effect. Our recent experimental study shows that the HDS of Bai-Hasan wide distillate derived from BaiHasan crude oil (that has a boiling range from initial boiling point to $823 \mathrm{~K}$ ) has the potential for meeting this demand. Hydrodesulfurization of such cut has been studied here under various operating conditions. An accurate process model for HDS process and the estimation of the kinetic parameters of the relevant reaction is very important to accurately model the process, so that the model can be effectively used for reactor design, operation and control.

Hydrodesulfurization process has the ability to reduce the contents of sulfur compounds. The effect of different hydrotreating operation variables such as reaction temperature and liquid hourly space velocity (LHSV) upon the quality of oil feedstock has also been investigated. It is noticed that the oil feedstock becomes more purified by removing the sulfur compounds with increasing in the reaction temperature and decreasing in LHSV.

An optimization technique, based on minimization of the sum of square errors (SSE) between the experimental and model predicted concentrations of sulfur compound is developed here to evaluate the kinetic 
parameters. Based on the objective function (SSE), the parameters estimated are found to be more accurate and the simulation results showed very good correspondence with the experimental data with an average absolute error of less than $5 \%$ among all results.

\section{References:}

Alcazar, L.A. and Ancheyta, J. (2007). Sensitivity analysis based methodology to estimate the best set of parameters for heterogeneous kinetic models. Chemical Engineering Journal, 128, pp 85.

Al-Humaidan, F.S. (2004). Modelling Hydrocracking of Atmospheric Residue by Discrete and Continuous Lumping. MSc Thesis, Al-Kuwait University.

Ali, L.H. and Abdul-Karim, E. (1986). The Oil, Origin, Composition and Technology. Mosul-Iraq.

Alvarez, A. and Ancheyta, J. (2008). Modeling residue hydroprocessing in a multi-fixed-bed reactor system. Applied Catalysis A: General, 351, pp 148.

Andari, M.K., Behbehani, H. and Stanislaus, A. (1996). Sulfur compound type distribution in Naphtha and gas oil fractions of Kuwaiti crude. Fuel Science \& Technology International, 14, pp 939.

Ancheyta, J. and Speight, J.G. (2007). Hydroprocessing of heavy oils and residua. USA, CRC Press.

Areff, H.A. (2001). The Effect of Operating Conditions on Vacuum Gas Oil Hydrotreating on Sulfur and Aromatics Content. MSc Thesis, University of Tikrit, College of Engineering, Chem. Eng. Department.

Armstrong, S.M., Sankey, B.M., and Voordouw, G. (1997). Evaluation of sulfuate reducing bacteria for desulfurizing bitumen or its fractions. Fuel, 76, pp 223.

Bhaskar, M., Valavarasu, G., Meenakshisundaram, A. and
Balaraman, K.S. (2002). Application of a Three Phase Heterogeneous Model to analyse the Performance of a Pilot Plant Trickle Bed Reactor. Petroleum Science and Technology, 20, pp 251.

Hsu, Ch.S. and Robinson, P.R. (2006). Practical Advances in Petroleum Processing. New York, Springer.

Isoda, T., Kusakabe, K., Morooka, Sh. and Mochida, I. (1998). Reactivity and Selectivity for the Hydrocracking of Vacuum Gas Oil over Metal-Loaded and Dealuminated Y-Zeolites. Energy \& Fuels, 12, 493.

Jarullah, A.T. Iqbal M. Mujtaba, Alastair S. Wood. (2011a). Kinetic Parameter Estimation and Simulation of Trickle Bed Reactor for Hydrodesulfurization of Crude Oil. Chemical Engineering Science, 66, pp 859.

Jarullah, A.T. Iqbal M. Mujtaba, Alastair S. Wood. (2011b) Kinetic model development and simulation of simultaneous hydrodenitrogenation and hydrodemetallization of crude oil in trickle bed reactor. Fuel, 90, pp 2165.

Jarullah, A.T. Iqbal M. Mujtaba, Alastair S. Wood. (2011c). Improvement of the Middle Distillate Yields during Crude Oil Hydrotreatment in a Trickle Bed Reactor. Energy \& Fuels, 25, pp 773.

Jarullah, A.T. Iqbal M. Mujtaba, Alastair S. Wood. (2012). Improving Fuel Quality by Whole Crude Oil Hydrotreating: A Kinetic Model for Hydrodeasphaltenization in a Trickle Bed Reactor. Applied Energy, 94, pp 182.

Jary, J.H. (1994). Petroleum Refining Technology and Economics. $3^{\text {rd }} \mathrm{Ed}$.

Jimenez, F., Nunez, M. and Kafarov, V. (2007a). Modeling of industrial reactor for hydrotreating of vacuum gas oils Simultaneous hydrodesulfurization, hydrodenitrogenation and hydrodearomatization reactions. 
Chemical Engineering Journal, 134, pp 200.

Jimenez, F., Ojeda, K., Sanchez, E., Kafarov, V. and Filho, R.M. (2007b). Modeling of trickle bed reactor for hydrotreating of vacuum gas oils: effect of kinetic type on reactor modelling. Computer Aided Chemical Engineering, 24, pp 515.

Khalfhallah, H.A. (2009). Modelling and optimization of Oxidative Desulfurization Process for Model Sulfur Compounds and Heavy Gas Oil. $\mathrm{PhD}$ Thesis. University of Bradford.

Korsten, H. and Hoffmann, U. (1996). ThreePhase Reactor Model Pilot TrickleBed for Hydrotreating in Reactors. AIChE J., 42, pp 1350.

Kumar, V.R., Balaraman, K.S., Rao, V.S.R. and Ananth, M.S. (2001). Performance study of certain commercial catalysts in Hydrodesulfurization of Diesel Oils. Petroleum Science and Technology, 19, pp 1029.

Lababidi, H.M.S., Shaban, H.I., Al-Radwan, S. and Alper, E. (1998). Simulation of an Atmospheric Residue Desulfurization Unit by Quasi-Steady State Modeling. Chem. Eng. Technol., 21, pp 193.

Macı́as, M.J. and Ancheyta, J. (2004). Simulation of an isothermal hydrodesulfurization small reactor with different catalyst particle shapes. Catal. Today, 98, pp 243.

Mederos, F.S. and Ancheyta, J. (2007). Mathematical modeling and simulation of hydrotreating reactors: Cocurrent versus countercurrent operations. Applied Catalysis A: General, 332, pp 8.
Rao, S.K. Imam, R. Ramanathan, K., and Pushpavanam, S. (2009). Sensitivity Analysis and Kinetic Parameter Estimation in a Three Way Catalytic Converter. Ind. Eng. Chem. Res., 48, pp 3779.

Resendiz, E., Ancheyta, J., Rosales-Quintero, A. and Marroquin, G. (2007). Estimation of activation energies during hydrodesulfurization of middle distillates. Fuel, 86, pp 1247.

Rodriguez, M.A. and Ancheyta, J. (2004). Modeling of Hydrodesulfurization (HDS), Hydrodenitrogenation (HDN), and the Hydrogenation of Aromatics (HDA) in a Vacuum Gas Oil Hydrotreater. Energy Fuels, 18, pp 789.

Ryan, J.F. (1998). Biotech Blooms in Bavaria. Today's Chemist at Work, 7, pp 84.

Speight, J.G. (2006). The Chemistry and Technology of Petroleum. $4^{\text {th }}$ edition. CRC Press/Taylor \& Francis, Boca Raton, FL.

Stacy, C.D., Susan, W.D. and Report, G.B. (2008). Transportation energy data book. Prepared for the office of energy efficiency and renewable energy U.S. Department of energy.

Stell, J. (2003). Worldwide refineries, capacities as of January 1; Oil \& Gas J, 101(49), December 22.

Swain, E.J. (1998). U.S. refining crude slates continue towards heavier feeds, higher sulfur contents. Oil \& Gas Journal, 96, pp 43.

Waguespack, K.G. and Healey, J.F. (1998). Manage crude oil quality for refining profitability.

Processing, 77, pp 133.

Wauquier, J.P. (1995). Crude Oil: Petroleum Products; Process Flowsheets. Paris, Editions Technip. 


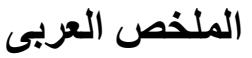

\section{نمذجة، محاكاة وامثلية عملية إزالة الكبريت بالهيذروجين لمقطر باي حسن الواسع}

\author{
شيماء علي حميد \\ قسم الهندسة الكيمياوية/ كلية الهنسة - جامعة تكريت، العر اق
}

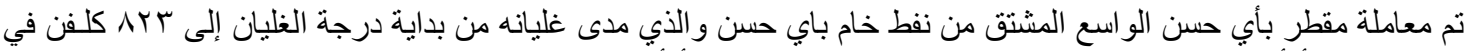

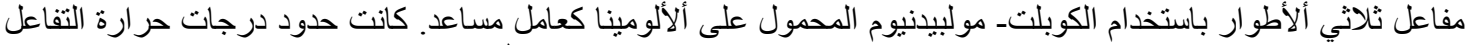

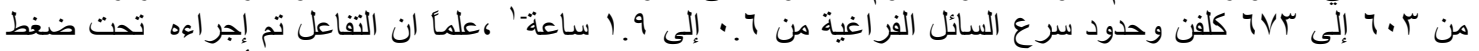

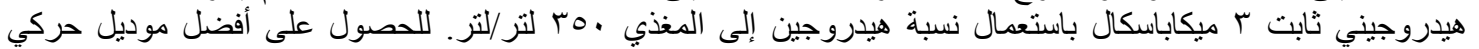

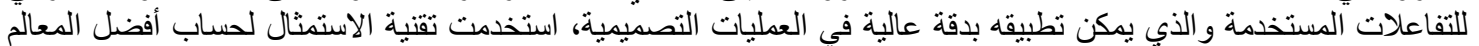
الحركية للتفاعل على أساس البرمجة غير الخطية. النتائج المستحصل عليها لئه أظهرت مو افقة كبيرة بين التر اكيز العملية والنظرية بنسبة اقل من 0\% ضمن معدل الخطأ المطلق لجميع النتائج. 